\title{
A Non-isolated High Step-up DC/DC Converter with Low EMI and Voltage Stress for Renewable Energy Applications
}

\author{
Solmaz Baharlou* and Mohammad Rouhollah Yazdani ${ }^{\dagger}$
}

\begin{abstract}
In this paper, a high step-up DC-DC PWM converter with continuous input current and low voltage stress is presented for renewable energy application. The proposed converter is composed of a boost converter integrated with an auxiliary step-up circuit. The auxiliary circuit uses an additional coupled inductor and a balancing capacitor with voltage doubler and switching capacitor technique to achieve high step-up voltage gain with an appropriate switch duty cycle. The switched capacitors are charged in parallel and discharged in series by the coupled inductor, stacking on the output capacitor. In the proposed converter, the voltage stress on the main switch is clamped, so a low voltage switch with low ON resistance can be used to reduce the conduction loss which results in the efficiency improvement. A detailed discussion on the operating principle and steady-state analyses are presented in the paper. To justify the theoretical analysis, experimental results of a $200 \mathrm{~W} 40 / 400 \mathrm{~V}$ prototype is presented. In addition, the conducted electromagnetic emissions are measured which shows a good EMC performance.
\end{abstract}

Keywords: Boost converter, Electromagnetic interference (EMI), Electromagnetic compatibility (EMC), High step-up DC-DC converter, Switched capacitors, Voltage stress

\section{Introduction}

The environmental problems and the shortage of fossil fuels have led to the search and utilization of renewable energy sources. Among them, photovoltaic (PV) sources, fuel cells and wind energy have attracted much attention in recent years [1-3]. Unfortunately, the output voltages of PV arrays and fuel cells are relatively low, but a high voltage DC bus is needed to supply the grid [4]. Hence, a high step-up DC-DC converter is often needed to increase this low voltage to an adequate level. In the widely employed module-integrated PV generation system, much research is focused on high step-up DC-DC converters to improve the total system efficiency [5-6].

In step-up applications, the conventional boost converter is usually applied due to its simple structure, continuous input current and high efficiency. However, in high stepup applications with high output voltage, it suffers from extremely high duty cycles, high conducting losses, high voltage stress across the switching devices and high reverse recovery losses [7]. Many techniques have been presented in literatures to avoid these problems and extend the voltage gain of conventional boost converter.

A quadratic three-level boost converter is proposed in [8] to increase the voltage gain with low switch voltage stress and continuous input current. However, the current

$\dagger$ Corresponding Author: Dept. of Electrical Engineering, Isfahan (Khorasgan) Branch, Islamic Azad University, Isfahan, Iran.

(m.yazdani@khuisf.ac.ir)

* Dept. of Electrical Engineering, Isfahan (Khorasgan) Branch, Islamic Azad University, Isfahan, Iran

Received: August 16, 2016; Accepted: February 17, 2017 stress is high and the voltage stress of the diode in the last stage is equal to the high output voltage leading to more losses. In [9-10], switched-capacitor-based boost converters with only one switch are presented. In these converters not only the input current is continuous, but also the switch voltage stress is significantly reduced and the gain is increased. However, the number of semiconductor devices is high and the conduction loss is considerable.

The coupled-inductor-based boost converters are one of the best options for high step-up applications due to their low switches voltage stress and high power density. In these converters, a coupled inductor can serve as a transformer that is used to extend the voltage gain. The cascade [11] and stacked [12] coupled-inductor boost converters are the basic structures of the coupled-inductorbased boost converters. In these converters, the reverse recovery of the output diode is eliminated by the leakage inductance of coupled-inductor and also by increasing turn ratio of the coupled-inductor.

By combining other techniques, e.g. switched capacitors and voltage doublers, with these two converters, many other high step-up converters have been obtained [13-15]. In the stacked coupled-inductor converters, an auxiliary circuit consisted of an inductor which is coupled with the boost converter inductor, is stacked at the output.

The voltage stress of the switch in these converters is clamped to the output voltage. However, the input current is pulsed and due to the fact that the input voltage is low, the RMS of input current is high. Thereby the conduction losses are high and a large input filter is needed. In the cascade coupled-inductor boost converters, an auxiliary 
step-up circuit including an inductor is tapped with the boost converter inductor and placed after the main diode [16]. However, these converters require an auxiliary clamp or snubber circuit to suppress the voltage spike across switch, caused by the leakage inductance. Also, the input current is not continuous as in a conventional boost converter and as the turns ratio of the coupled inductors increase to further enlarge the voltage gain, input current ripple becomes larger in return leading to a large input filter too.

In order to reach a high step-up converter having the benefits of the coupled-inductor-based boost converters, without large input current, some boost converters integrated with coupled inductor assisted auxiliary stepup circuits are proposed in [17-19] which are suitable for low-to-medium power applications. In these converters, the power should be processed twice; hence the conduction losses are significant. In [19], the voltage stress of output diode is high and considering the number of components, the overall voltage gain is low and limited to the transformer turn-ratio.

In this paper, an alternative structure, which is based on a boost converter integrated with an isolated step-up circuit, is investigated to reach a high step-up converter with continuous input current, low power devices voltage stress. So, in the proposed converter, high quality elements can be used and the conduction losses can be decreased. The auxiliary circuit uses an additional coupled inductor and a balancing capacitor with voltage doubler and switching capacitor technique to achieve high step-up voltage gain with an appropriate switch duty cycle. Moreover, the leakage inductance of the coupled inductor limits the current falling rate, which alleviates the reverse recovery problem on the main diode.

This paper arranged to six sections. In section 2 , the operation principles of the proposed converter are presented. The important specifications of the proposed converter such as its voltage gain are discussed in section 3 and the design procedure is shown in section 4 . The experimental results of the prototype are offered in section 5. Since power converters can be noise sources for other nearby systems [20], conducted EMI of the proposed converter and another high step-up converter with coupled inductor are examined and compared in section 6. Finally, conclusion remarks are presented in section 7 .

\section{Proposed Converter Operation}

Fig. 1 shows the proposed high step-up DC/DC converter. The equivalent circuit model of the coupled inductor includes a magnetizing inductor $L_{m}$, a leakage inductor $L_{l k}$ and an ideal coupled inductor $\left(L_{P}: L_{S}\right)$. In order to simplify the analysis of the proposed converter, some assumptions are considered as follows:

1) All components are ideal but the reverse recovery issues

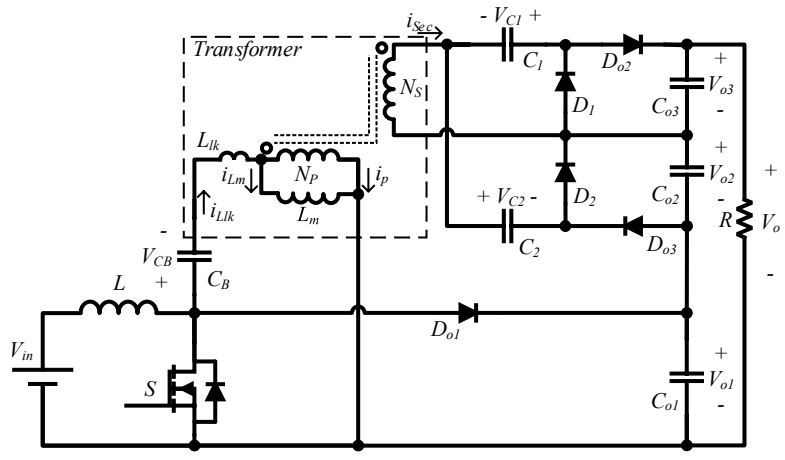

Fig. 1. The circuit configuration of the proposed converter

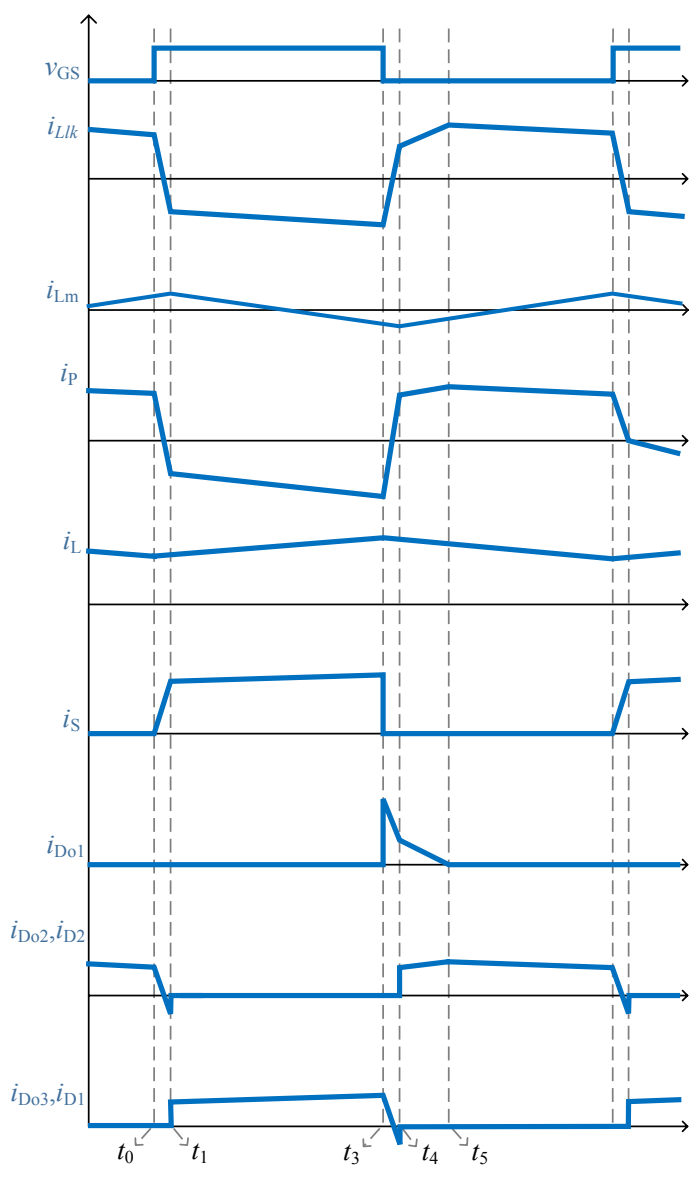

Fig. 2. Typical waveforms of the proposed converter

of diodes are shown in the key waveforms and also the leakage inductance of the coupled inductor is considered.

2) Capacitors are large enough; so that their voltages are considered to be constant during one switching period.

3) Inductor $L$ is large enough, thus its current is in continuous current mode (CCM).

4) The coupling-coefficient of the coupled-inductor $k$ is equal to $L_{m} /\left(L_{m}+L_{l k}\right)$ and the turn-ratio of the ideal coupled inductor, $n$ is equal to $N_{s} / N_{p}$.

The proposed converter has six operation intervals in one switching cycle at CCM condition. Fig. 2 and Fig. 3 
show typical waveforms and equivalent circuit of each interval. Before the first interval, it is assumed that the main switch was off and the $I_{l k}$ was equal to the current of the input inductor. Thus, the whole input inductor current is being transferred through coupled inductor toward the secondary side. In the secondary side, diodes $D_{2}$ and $D_{o 2}$ are $\mathrm{ON}$ and $C_{03}$ and $C_{1}$ capacitors are charging and discharging respectively through $L_{S}-C_{1}-D_{o 2}-C_{o 3}$ path and $C_{2}$ is charging through $L_{S}-C_{2}-D_{2}$ path. The detailed operation of each interval is presented as follows.

Interval I $\left[t_{0}-t_{1}\right]$, Fig. 3(a): By turning the switch on, the first interval starts and the input inductor current increases. The trurn-on of the switch is under zero current (ZC) due to the existence of series inductor. Also, the $C_{B}$ voltage is placed across the primary side of the coupled inductor which results in decreasing leakage inductance current, $i_{L l k}$. Therefore, the current passing through the primary transformer winding, $D_{o 2}$ and $D_{2}$ decreases linearly in a way that the $i_{L l k}$ reaches the magnetizing inductance current

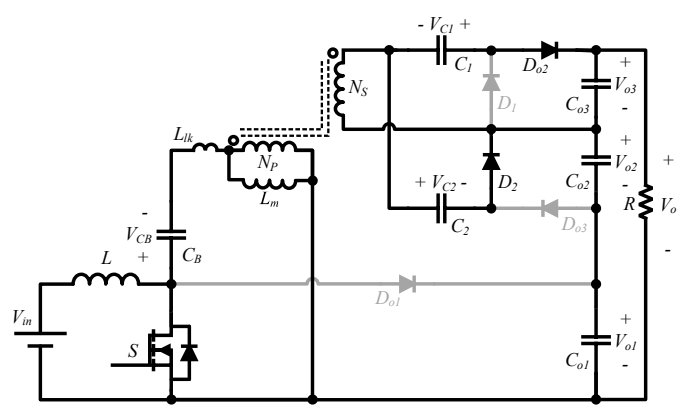

(a)

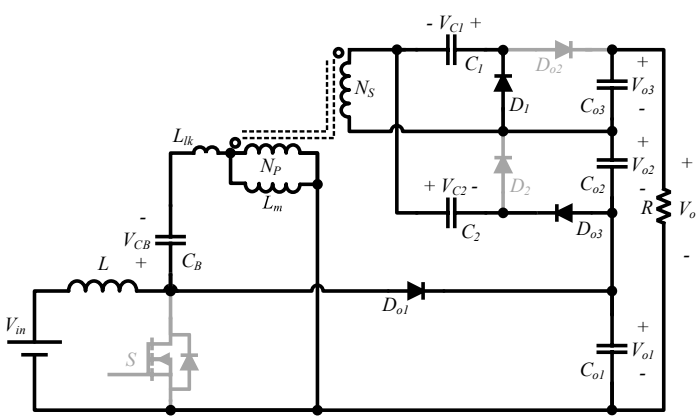

(c) at the end of this mode. In fact, the primary current of transformer gets zero. When the transformer primary current gets zero, $D_{o 2}$ and $D_{2}$ start to turn off. When $D_{o 2}$ and $D_{2}$ are turned off, this interval ends. The equations of the $i_{L}$ and $i_{L l k}$ are as follows:

$$
\begin{gathered}
i_{L}(t)=i_{L}\left(t_{0}\right)+\frac{V_{i n}}{L_{l k}} \cdot\left(t-t_{0}\right) \\
i_{L \mathrm{k}}(t)=i_{L}\left(t_{0}\right)-\frac{V_{C B}+\frac{N_{p}}{N_{S}} \cdot \frac{V_{o 2}}{2}}{L_{l k}} \cdot\left(t-t_{0}\right)
\end{gathered}
$$

Interval II $\left[t_{1}-t_{2}\right]$, Fig. 3(b): This interval begins by reversing the transformer primary current and the diodes $D_{1}$ and $D_{o 3}$ turn on. During this interval, the $C_{B}$ capacitor voltage is placed at the primary winding and the $i_{L l k}$ continues decreasing. The inductor current of $L$ increases continuously (according to (1)) and the $i_{L m}$ starts decreasing.

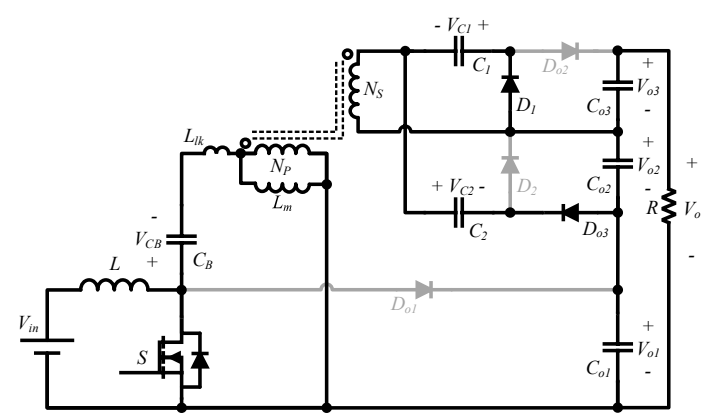

(b)

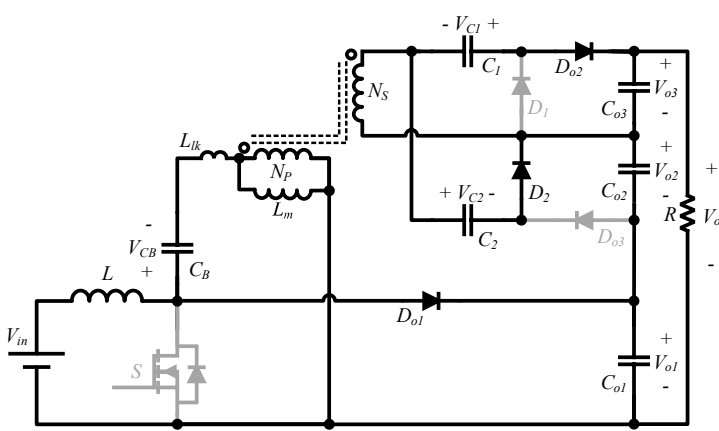

(d)

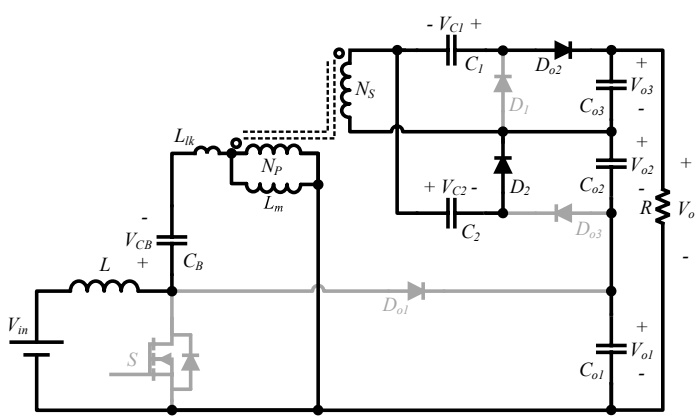

(e)

Fig. 3. Equivalent circuit of each operating mode, (a) Interval $1\left[t_{0}-t_{1}\right]$, (b) Interval $2\left[t_{1}-t_{2}\right]$, (c) Interval $3\left[t_{2}-t_{3}\right]$, (d) Interval $4\left[t_{3}-t_{4}\right]$ and (e) Interval $5\left[t_{4}-t_{5}\right]$. 
Both $C_{1}$ and $C_{o 2}$ are charging and $\mathrm{C}_{2}$ is discharging. The equations of the $i_{L l k}, i_{L m}$ and transformer primary current, $i_{P}$ are as following:

$$
\begin{gathered}
i_{L m}(t)=i_{L m}\left(t_{1}\right)-\frac{V_{C 1} \cdot \frac{N_{P}}{N_{S}}}{L_{m}} \cdot\left(t-t_{1}\right) \\
i_{L l k}(t)=i_{L k}\left(t_{1}\right)-\frac{V_{C B}-V_{C 1} \cdot \frac{N_{P}}{N_{S}}}{L_{k}} \cdot\left(t-t_{1}\right) \\
i_{P}(t)=\left[\frac{V_{C 2} \cdot \frac{N_{P}}{N_{S}}}{L_{m}}-\frac{V_{C B}-V_{C 1} \cdot \frac{N_{P}}{N_{S}}}{L_{k}}\right] \cdot\left(t-t_{1}\right)
\end{gathered}
$$

This interval continues until the time that the switch remains on. At the end of this interval, the current of magnetizing and $i_{L l k}$ are negative.

Interval III $\left[t_{2}-t_{3}\right]$, Fig. 3(c): At $t_{2}$, the switch turns OFF. After turning the switch OFF, $L$ and $L_{l k}$ currents start passing through $D_{o l}$ and the polarity of the transformer and $L$ voltages is reversed. Therefore, during this interval, the $i_{L}$ and $i_{L l k}$ start decreasing and increasing respectively.

It should be noticed that $i_{L l k}$ starts from a negative value and continues to increase which results in reducing the current passing through the transformer in a way that at the end of this mode, the $i_{L l k}$ reaches $i_{L m}$ and finally the transformer would be zero. Similar to the previous interval, the magnetizing inductance current of this interval increases toward the negative direction. This interval finishes by turning the $D_{1}$ and $D_{o 3}$ OFF. The equation of magnetizing inductance current is like (3) and the equations of the $i_{L l k}$ and transformer primary current are:

$$
\begin{aligned}
& i_{L l k}(t)=i_{L k}\left(t_{2}\right)+\frac{V_{o 1}+V_{C 1} \cdot \frac{N_{P}}{N_{S}}-V_{C B}}{L_{k}} \cdot\left(t-t_{2}\right) \\
& i_{P}(t)=i_{P}\left(t_{2}\right)+\left[\frac{V_{C 1} \cdot \frac{N_{P}}{N_{S}}}{L_{m}}+\frac{V_{o 1}+V_{C 1} \cdot \frac{N_{P}}{N_{S}}-V_{C B}}{L_{k}}\right] .\left(t-t_{2}\right)
\end{aligned}
$$

Also, the equations of $i_{L}$ and $D_{o l}$ current are as below:

$i_{L}(t)=i_{L}\left(t_{2}\right)+\frac{V_{i n}-V_{o 1}}{L} \cdot\left(t-t_{2}\right)$

$i_{D 2}(t)=i_{L}\left(t_{2}\right)-i_{L k}\left(t_{2}\right)+\left[\frac{V_{i n}-V_{o 1}}{L}-\frac{V_{o 1}+V_{C 1} \cdot \frac{N_{P}}{N_{S}}-V_{C B}}{L_{k}}\right]\left(t-t_{2}\right)$

It is necessary to mention that is a negative amount in the foregoing equation.

Interval IV $\left[t_{3}-t_{4}\right]$, Fig. $3(\mathrm{~d})$ : At the beginning of this interval, the direction of the secondary current of transformer is in positive direction, consequently $D_{o 2}$ and $D_{2}$ diodes would turn $\mathrm{ON}$ and $C_{o 3}$ and $C_{1}$ capacitors start charging and discharging through $L_{S}-C_{1}-D_{o 2}-C_{o 3}$ path respectively. Also, $C_{2}$ capacitor starts charging through $L_{S}-C_{2}-D_{2}$ direction. $i_{L l k}$ continues until the leakage inductance current would be equal to the with $L$ inductor current at the end of this interval and $D_{o l}$ diode turns OFF. Magnetizing inductance current, $\mathrm{i}_{L m}$ also starts increasing. The equation of $i_{L}$ is similar to the interval III and the equations of the $i_{L m}, i_{L l k}$ and the transformer primary and secondary current are as the followings:

$$
\begin{aligned}
& i_{L m}(t)=i_{L m}\left(t_{3}\right)+\frac{V_{C 2} \cdot \frac{N_{P}}{N_{S}}}{L_{m}} \cdot\left(t-t_{3}\right) \\
& i_{L l k}(t)=i_{L k}\left(t_{3}\right)+\frac{V_{o 1}-V_{C 1} \cdot \frac{N_{P}}{N_{S}}-V_{C B}}{L_{k}} \cdot\left(t-t_{3}\right) \\
& i_{P}(t)=\frac{N_{S}}{N_{P}} \cdot i_{\mathrm{Sec}}(t) \\
& =\left[\frac{V_{o 1}-V_{C 1} \cdot \frac{N_{P}}{N_{S}}-V_{C B}}{L_{k}}-\frac{V_{C 2} \cdot \frac{N_{P}}{N_{S}}}{L_{m}}\right] \cdot\left(t-t_{3}\right)
\end{aligned}
$$

Interval $\mathrm{V}\left[t_{4}-t_{5}\right]$, Fig. 3(e): This intervals starts when the $D_{o l}$ diode turns OFF. During this interval, the switch remains OFF and the input inductor current is being transferred toward the secondary side by the transformer. $D_{o 2}$ and $D_{2}$ diodes are $\mathrm{ON}$ at the secondary side and $C_{o 3}$ and $C_{1}$ capacitors are charging and discharging respectively through $L_{S}-C_{1}-D_{o 2}-C_{o 3}$ path. $C_{2}$ capacitor is also charging through $L_{S}-C_{2}-D_{2}$ direction. The equations of $i_{L}$, $i_{L m}, i_{L l k}$ and the transformer primary and secondary currents are as the followings:

$$
\begin{aligned}
& i_{L m}(t)=i_{L m}\left(t=t_{4}\right)+\frac{V_{C 2} \cdot \frac{N_{P}}{N_{S}}}{L_{m}} \cdot\left(t-t_{4}\right) \\
& i_{L}(t)=i_{L l k}(t)=i_{L k}\left(t_{4}\right)-\frac{V_{C B}+V_{C 1} \cdot \frac{N_{P}}{N_{S}}-V_{i n}}{L_{l k}+L_{m}} \cdot\left(t-t_{4}\right) \\
& i_{P}(t)=\frac{N_{S}}{N_{P}} \cdot i_{\text {Sec }}(t) \\
& =i_{p}\left(t_{4}\right)-\left[\frac{V_{C B}+V_{C 1} \cdot \frac{N_{P}}{N_{S}}-V_{i n}}{L_{l k}+L_{m}}+\frac{V_{C 2} \cdot \frac{N_{P}}{N_{S}}}{L_{m}}\right] \cdot\left(t-t_{4}\right)
\end{aligned}
$$

\section{Proposed Converter Specifications}

In order to show the benefits of the proposed converter, 
its main specifications are described.

\subsection{Voltage gain}

$V_{C B}, V_{C o 2}$ and $V_{C o 3}$ values can be defined according to the volt-second balance for magnetizing inductance :

$$
\begin{gathered}
V_{C B}=V_{i n} \\
V_{C o 2}=V_{C 03}=\frac{n \cdot k \cdot V_{i n}}{1-D}
\end{gathered}
$$

$V_{C o l}$ can be calculated by ignoring the duration time of the first and third intervals. This is because of very short time with respect to the switching period. $V_{C o l}$ can be determined using the $L$ volt-second balance for inductor:

$$
V_{C o 1}=\frac{D \cdot T+T_{1}-\left(T-D \cdot T-T_{1}\right) \cdot k \cdot\left(\frac{D}{1-D}\right)}{T_{1}} \cdot V_{i n}
$$

where $T_{l}$ can be determined by writing the current-second balance for $C_{O I}$ capacitor as below:

$$
T_{1}=\frac{2 \cdot I_{o} \cdot T}{I_{P}}
$$

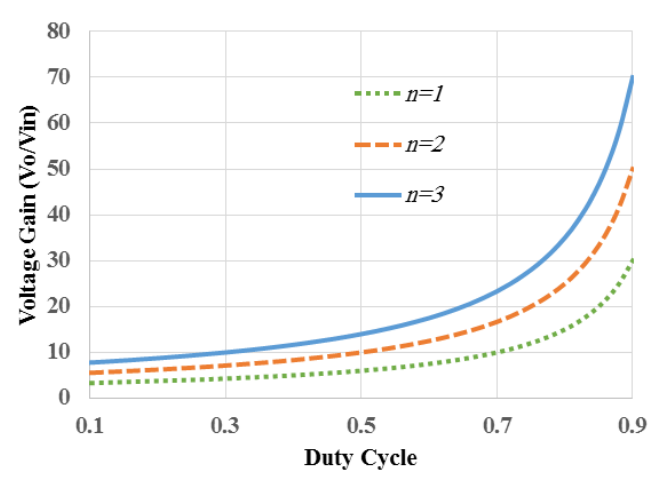

(a)

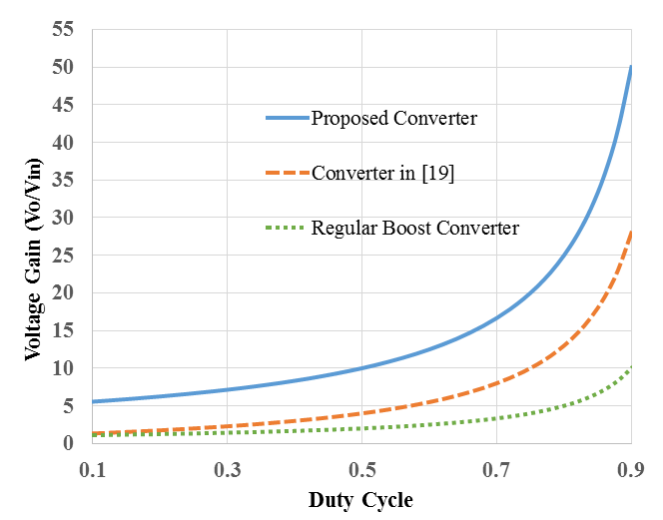

(b)

Fig. 4. (a) gain voltage of the proposed converter for various $n$ (b) gain voltage comparison for $n=2$ where $I_{P}$ can be estimated using the following equation by ignoring converter losses:

$$
I_{P}=\frac{P_{o}}{V_{i n}}+\frac{V_{i n} \cdot D \cdot T}{L}+\frac{k \cdot V_{i n} \cdot(1-D) \cdot T}{L_{m}}
$$

In order to reach a simple and approximate equation for the converter voltage gain, it is assumed that the coupling coefficient, $k$ is estimated by 1 . Thus, the following equation could be offered to describe the proposed converter gain.

$$
\frac{V_{o}}{V_{i n}}=\frac{1+2 . n}{1-D}
$$

Fig. 4(a) shows the voltage gain for various $n$. Fig. 4(b) compares the voltage gain of the proposed converter with the voltage gain of [19] and regular boost converter which shows the higher gain of the proposed converter.

\subsection{Voltage stress of the semiconductor devices}

According to the operation of the proposed converter, the voltage stress of the switch and $D_{O I}$ is:

$$
\overline{V_{S}}=\overline{V_{D o 1}}=V_{C o 1}
$$

Also the voltage stress of $D_{1}, D_{2}, D_{O 2}$ and $D_{O 3}$ are:

$$
\overline{V_{D 1}}=\overline{V_{D 2}}=\overline{V_{D o 2}}=\overline{V_{D o 3}}=V_{C o 2}
$$

From (23), it is obvious that the voltage stress of diodes in the proposed converter is much less than the isolated SEPIC converter and the converter proposed in [19]. It is noticeable that the output diodes of the isolated SEPIC converter suffer from high voltage spike and for this reason an auxiliary clamp circuit is need. But, in the proposed converter there is no voltage spike on the diodes.

\section{Design Procedure}

In order to design the proposed converter, at the first step, the maximum duty cycle is determined considering the suitable elements and the voltage stresses of the elements. After considering the maximum duty cycle, the coupled inductor turn-ratio can be defined by (21). Also, the value of $L_{m}$ and $L$ can be selected according to acceptable current ripple using the following equations:

$$
\begin{gathered}
L=\frac{V_{i n} \cdot \bar{D} \cdot T}{\Delta I} \\
L_{m}=\frac{V_{i n} \cdot(1-\underline{D}) \cdot T}{\Delta I}
\end{gathered}
$$


The capacitors values can be defined to have a constant voltage using current-second balance equations. Accordingly, $C_{B}$ can be expressed by:

$$
C_{B}=\frac{P_{o} \cdot(1-D) \cdot T}{V_{i n} \cdot \Delta V_{C B}}
$$

where $\Delta V_{C B}$ is the acceptable voltage ripple of $C_{B}$.

\section{Experimental Results}

In order to the verify the operation of the converter and the presented key waveforms, a $200 \mathrm{~W}$ prototype of the proposed converter is designed and implemented with the switching frequency of $100 \mathrm{kHz}$. In order to show the ability of providing high voltage gain, input voltage and output voltages of the prototype are $40 \mathrm{~V}$ and $400 \mathrm{~V}$, respectively. The values and types of the components are shown in Table 1. $L$ and $L_{m}$ and $C_{B}$ values are defined by (24), (25) and (26), respectively.

Fig. 5 shows the current and voltage waveforms of the converter switch which verifies the theoretical waveforms. According to this figure, the voltage stress of the switch is about $80 \mathrm{~V}$ which is much less than $400 \mathrm{~V}$ output voltage. This reduced switch voltage leads to the reduction of the switching losses because, the voltage is increased to lower amount at turn-off instant and the switch voltage is reduced from a lower voltage level at turn-on instant. Also, lower voltage rated MOSFETs usually have lower on resistance and so the conduction loss of the switch is decreased.

Table 1. Components value and specification

\begin{tabular}{c|c}
\hline Switch & IRFP260 \\
\hline Diodes & MUR460 \\
\hline $\mathrm{L}$ & $500 \mu \mathrm{H}$ \\
\hline $\mathrm{L}_{\mathrm{m}}$ & $100 \mu \mathrm{H}$ \\
\hline $\mathrm{N}_{\mathrm{s}} / \mathrm{N}_{\mathrm{p}}$ & 2 \\
\hline $\mathrm{C}_{1,2}, \mathrm{C}_{\mathrm{O} 1-3}$ & $10 \mu \mathrm{F}$ \\
\hline $\mathrm{C}_{\mathrm{B}}$ & $22 \mu \mathrm{F}$ \\
\hline
\end{tabular}

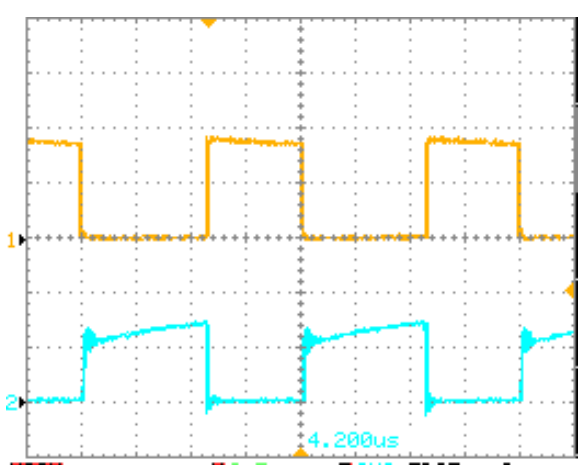

Fig. 5. Switch voltage (top) and current (bottom) waveforms, (voltage: $50 \mathrm{~V} / \mathrm{div}$, current: $10 \mathrm{~A} / \mathrm{div}$, time scale: $2.5 \mu \mathrm{s})$
Thereby, the overall efficiency of the converter can be increased.

Fig. 6 illustrates the $D_{O I}$ current and voltage waveforms which confirms that its voltage stress is similar to the voltage stress of the switch. Furthermore, the reverse recovery of this diode is not considerable; because its current rate is limited by leakage inductance and at its turnoff instant, the converter switch is off.

Fig. 7 and Fig. 8 show the current and voltage waveforms of $D_{1}, D_{2}, D_{O 2}$ and $D_{O 3}$ which indicate that the switch stress of these diodes are lower than $V_{O} / 2$. Also, the

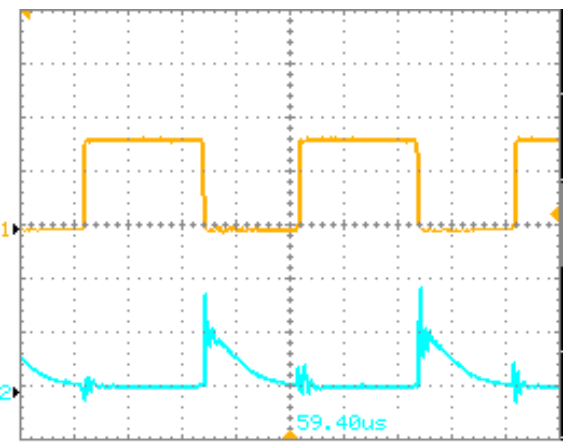

Fig. 6. The voltage (top) and current (bottom) waveforms of $D_{O l}$, (voltage: $50 \mathrm{~V} /$ div, current: $5 \mathrm{~A} / \mathrm{div}$, time scale: $2.5 \mu \mathrm{s})$

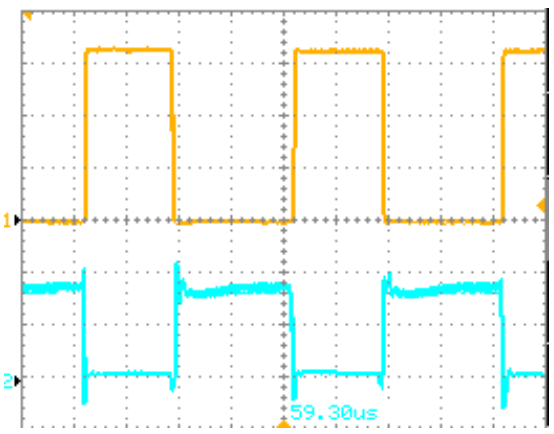

Fig. 7. The voltage (top) and current (bottom) waveforms of $D_{1}, D_{O 3}$ (voltage: $50 \mathrm{~V} / \mathrm{div}$, current: $0.5 \mathrm{~A} / \mathrm{div}$, time scale: $2.5 \mu \mathrm{s})$

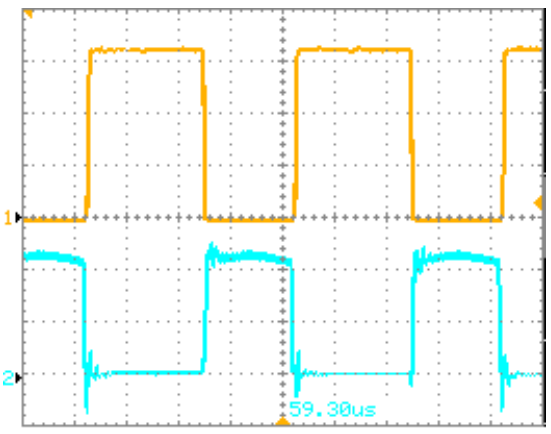

Fig. 8. The voltage (top) and current (bottom) waveforms of $D_{2}, D_{O 2}$ (voltage: $50 \mathrm{~V} / \mathrm{div}$, current: $0.5 \mathrm{~A} / \mathrm{div}$, time scale: $2.5 \mu \mathrm{s})$ 


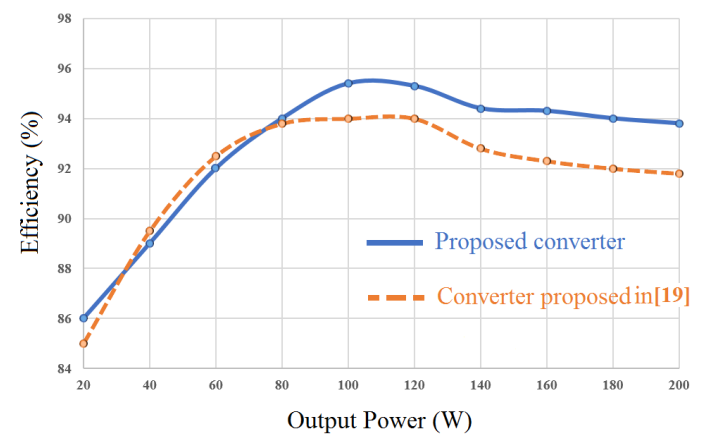

Fig. 9. Efficiency curves of proposed and [19] converters

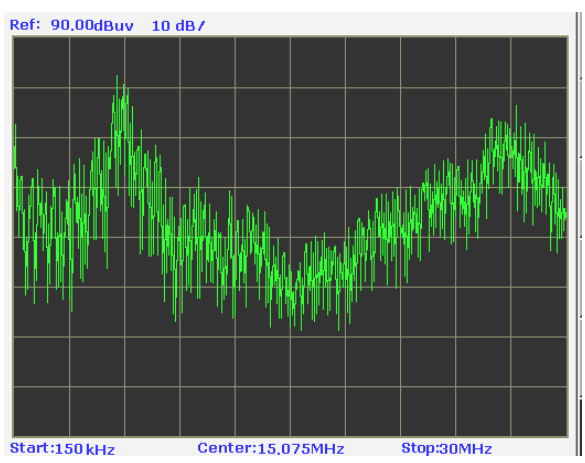

(a)

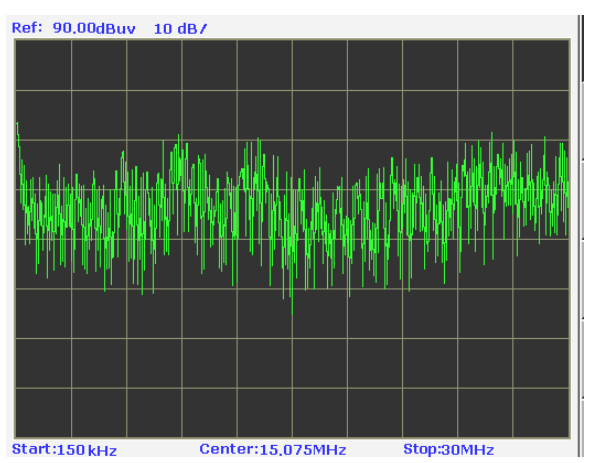

(b)

Fig. 10. Conducted EMI: (a) converter in [19]; (b) proposed converter (Ver. axis: 10-90 dB $\mu \mathrm{V}$, Hor. axis: 0.15$30 \mathrm{MHz})$

current reduction slope of $D_{1}, D_{2}, D_{O 2}$ and $D_{O 3}$ is low at turn-off instant due to the existence of the leakage inductance. Thus, their reverse recovery is not significant.

Fig. 9. shows the efficiency curve of proposed high stepup converter and converter in [19] with similar components as a function of output power. The proposed converter has improved the efficiency because its voltage gain can be achieved by lower duty cycle and also the current is transferred to the SEPIC section in both switch turn-off and turn-on situations leading to lower conduction losses. In addition, the reverse recovery problem of diodes are alleviated, the diodes losses caused the reverse recovery are decreased and the converter overall efficiency is further increased.

\section{Conducted EMI Measurement}

Conducted EMI measurement of the proposed and [19] converters are presented and compared in this section based on the experimental results. EMI is measured according to CISPR22 standard using line impedance stabilization network (LISN) and spectrum analyser (peak detection) as shown in Fig. 10. According to Fig. 10(a) and (b), the main conducted EMI peak of [19] and the proposed converter are around 82.5 and $73.5 \mathrm{~dB} \mu \mathrm{V}$ respectively which shows the main peak is $9 \mathrm{~dB} \mu \mathrm{V}$ lower than that of [19], indicating another benefit of the proposed converter from EMC viewpoint.

More conducted electromagnetic emissions of [19] is due to high frequency and high amplitude spikes on switch current and voltage waveforms and also the diodes reverse recovery problem.

\section{Conclusions}

According to the presented review of non-isolated high step-up converters, boost converters integrated with coupled inductor assisted auxiliary step-up circuits are one of the best concepts for use in low-to-medium power, high step-up application. In this paper, a new high step-up DC-DC PWM converter with continuous input current is introduced considering this concept. After analyzing the operation modes of the proposed converter and discussing its specification, the experimental results are presented which confirms the high voltage gain and low voltage stress of the semiconductor components. In addition to higher gain, the efficiency of the proposed converter is compared with another high step-up boost converter integrated with coupled inductor which shows the efficiency of the proposed converter is around $2 \%$ better than it at the nominal load. Also, the proposed converter has low conducted EMI which indicates another benefit of the proposed converter.

\section{References}

[1] S. Subramanian and T. Subbaiyan, "A Simple Power Management Scheme with Enhanced Stability for a Solar PV/Wind/Fuel Cell Fed Standalone Hybrid Power Supply using Embedded and Neural Network Controller," J. Electr. Eng. Technol., vol. 9, no. 5, pp. 1454-1470, 2014.

[2] Mi-Young Kim and Yong-Un Song, "The Analysis of Active Power Control Requirements in the Selected Grid Codes for Wind Farm," J. Electr. Eng. Technol., vol. 10, no. 4, pp.1408-1414, 2015.

[3] M. A. Khlifi, "Study and Control of Photovoltaic Water Pumping System," J. Electr. Eng. Technol., vol. 
11, no. 1, pp. 117-124, 2016.

[4] B. Liu, S. Duan, and T. Cai, "Photovoltaic DCbuilding-module-based BIPV system-concept and design considerations," IEEE Trans. Power Electron., vol. 26, no. 5, pp. 1418-1429, 2011.

[5] F. L. Tofoli, D. d. C. Pereira, W. Josias de Paula and D. d. S. Oliveira Júnior, "Survey on non-isolated high-voltage step-up dc-dc topologies based on the boost converter," IET Power Electron., vol. 8, no. 10, pp. 2044-2057, 2015.

[6] K. I. Hwu and T. J. Peng, "High Step-Up Converter with Hybrid Structure Based on One Switch," J. Electr. Eng. Technol., vol. 10, no. 4, pp.1566-1577, 2015.

[7] O. Abutbul, A. Gherlitz, Y. Berkovich, and A. Ioinovici, "Step-up switching-mode converter with high voltage gain using a switched-capacitor circuit," IEEE Trans. Syst. I, Fundam. Theory Appl., vol. 50, no. 8, pp. 1098-1102, 2003.

[8] D. Novaes, Y.R. Rufer, A. Barbi, "A new quadratic, three-level, dc/dc converter suitable for fuel cell applications," in Proc. Power Conversion Conf., 2007, pp. 601-607.

[9] E. H. Ismail, M. A. Al-Saffar, A. J. Sabzali and A. A. Fardoun, "A Family of single-switch PWM converters with high step-up conversion ratio," in IEEE Trans. Circuits and Systems I: Regular Papers, vol. 55, no. 4, pp. 1159-1171, 2008.

[10] J. C. Rosas-Caro, J. M. Ramirez, F. Z. Peng and A. Valderrabano, "A DC-DC multilevel boost converter," IET Power Electron., vol. 3, no. 1, pp. 129-137, 2010.

[11] Q. Zhao and F. C. Lee, "High-efficiency, high step-up dc-dc converters," IEEE Trans. Power Electron., vol. 18 , no. 1, pp. $65-73,2003$.

[12] T. J. Liang and K. C. Tseng, "Analysis of integrated boost-flyback step up converter," in Proc. Inst. Elect. Eng. - Elect. Power Appl., vol. 152, no. 2, pp. 217225, 2005.

[13] Y. P. Hsieh, J. F. Chen, T. J. Liang, and Y. L. -Sheng, "Analysis and implementation of a novel singleswitch high step-up dc-dc converter," IET Power Electron., vol. 5, no. 1, pp. 11-21, 2012.

[14] Y.-P. Hsieh, J.-F. Chen, T.-J. Liang, and L.-S. Yang, "Novel high step-up DC-DC converter with coupledinductor and switched-capacitor techniques," IEEE Trans. Ind. Electron., vol. 59, no. 2, pp. 998-1007, 2012.

[15] K. C. Tseng, J. T. Lin, and C. C. Huang, "High stepup converter with three-winding coupled inductor for fuel cell energy source applications," IEEE Trans. Power Electron., vol. 30, no. 2, pp. 574-581, 2015.

[16] H. Liu, H. Hu, H. Wu, Y. Xing and I. Batarseh, "Overview of High-Step-Up Coupled-Inductor Boost Converters," IEEE Jour. of Emerg. and Sel. Top. in Power Electron., vol. 4, no. 2, pp. 689-704, 2016.

[17] X. Hu, and C. Gong, "A high voltage gain DC-DC converter integrating coupled-Inductor and diodecapacitor Techniques," IEEE Trans. Power Electron., vol. 29, no. 2, pp. 789-800, 2014.

[18] Y. Deng, Q. Rong, W. Li, Y. Zhao, J. Shi, and X. He, "Single-switch high step-up converters with built-in transformer voltage multiplier cell," IEEE Trans. Power Electron., vol. 27, no. 8, pp. 3557-3567, 2012.

[19] K. B. Park, G. W. Moon, and M. J. Youn, "Non isolated high step-up boost converter integrated with SEPIC converter," IEEE Trans. Power Electron., vol. 25, no. 9, pp. 2266-2275, 2010.

[20] C. Krishnakumar, et al., "A New Random PWM Technique for Conducted-EMI Mitigation on Cuk Converter," J. Electr. Eng. Technol., vol. 10, no. 3, pp. 916-924, 2015.

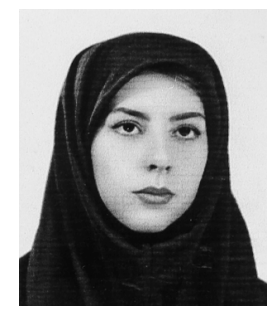

Solmaz Baharlou She received his B.S. and M.S. degree in electrical engineering from Najafabad Branch, Islamic Azad University and Isfahan (khorasgan) Branch, Islamic Azad University, Isfahan, Iran in 2013 and 2016, respectively. His research interests include dc-dc converters.

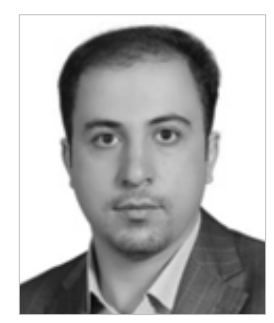

Mohammad Rouhollah Yazdani $\mathrm{He}$ received B.S., M.S. and $\mathrm{PhD}$ degrees in electrical engineering from the Isfahan University of Technology, Najafabad Branch, Islamic Azad University and Sciences \& Research Branch, Islamic Azad University in 2001, 2004 and 2011, respectively. Since 2011, he has been a Faculty Member at the Dept. of Electrical Engineering, Isfahan (Khorasgan) Branch, Islamic Azad University, Isfahan, Iran. His research interests include soft-switching converters, EMI reduction techniques, signal integrity and EMC issues. 